\title{
EVALUATION OF THE LAME'S CONSTANTS IN THEORY OF ELASTICITY BY ULTRASONIC MEASURMENTS
}

\author{
AleXANder Popov ${ }^{1 *}$, GeOrgy Dobrev ${ }^{2}$ \\ ${ }^{1}$ Institute of Mechanics, Bulgarian Academy of Sciences, Acad. G. Bonchev \\ St., Bl. 4, 1113, Sofia, Bulgaria \\ ${ }^{2}$ Institute of Metal Science, Equipment and Technologies, Bulgarian Academy \\ of Sciences, Shipchenski prohod St. 67, 1574, Sofia, Bulgaria
}

[Received 25 July 2018. Accepted 18 February 2019]

doi: 10.7546/JTAM.49.19.01.06

\begin{abstract}
The evaluation of Lame's constants $(\lambda ; \mu)$ is taken in theory of elasticity. An interest in practice is the possibility of non-destructive evaluation (NDE) of $(\lambda ; \mu)$ by measuring ultrasound wave propagation longitudinal and transversal velocities $\left(V_{L} ; V_{T}\right)$ with unilateral access to the test sample.
\end{abstract}

KEY WORDS: Lame's constants; ultrasonic velocities.

\section{INTRODUCTION}

The conventional method for determining Lame's constants of homogeneous elastic isotropic material $(\lambda ; \mu)[1]$ is by mechanical testing. The method is destructive. An alternative of mechanical testing is by measuring of longitudinal and transversal velocity $\left(V_{L} ; V_{T}\right)$ [2]. It is non-destructive evaluation (NDE). This method requires two-sided access to the test specimen. The numeric values of $(\lambda ; \mu)$ are obtain by means of

$$
\begin{aligned}
& \rho V_{L}^{2}=\lambda+2 \mu, \\
& \rho V_{T}^{2}=\mu .
\end{aligned}
$$

Density of the material is $\rho$. In this case, a significant disadvantage is the need to use two transducers: a conventional transducers with X-cut of piezo plate for longitudinal ultrasonic waves and a specialized transducers with Y-cut of piezo plate transducers for transverse ultrasonic waves. Knowing [1] the relationships between $(\lambda ; \mu)$ and the technical elasticity modules $(E ; \nu ; G ; K)$ - Young module, Poison's coefficient, shear module, volume module through the physical moduli of elasticity (the Lame constants). These are

$$
E=\frac{\mu(3 \lambda+2 \mu)}{\lambda+\mu}
$$

\footnotetext{
*Corresponding author e-mail: alpopov@abv.bg
} 


$$
\begin{aligned}
& \nu=\frac{\lambda}{2(\lambda+\mu)}, \\
& G=\mu, \\
& K=\lambda+\frac{2}{3} \mu .
\end{aligned}
$$

The above brings about to the need to develop NDE methods for estimation of Lame's constants in case of unilateral access to the measured object. These are the cases of NDE of pipelines, petrol storage tanks and other. The solution to these tasks has two stages:

A) Development of methodology for evaluation of the velocities $\left(V_{L} ; V_{T}\right)$ in unilateral access to the measured sample.

B) Development of methodology for evaluation of physical modules of elasticity $(\lambda ; \mu)$, respectively the technical modules of elasticity $(E ; \nu ; G ; K)$ by measuring of the velocities $\left(V_{L} ; V_{T}\right)$, at unilateral access to the measured sample. In this case two conventional transducers (X-cut of piezo plate) with a variable angle are used.

\section{Waves Propagation with High Frequency}

For description of waves propagation high frequency the eikonal equations [3] are used

$$
\begin{aligned}
& |\nabla T \cdot \nabla T|=\frac{1}{V_{L}^{2}}, \\
& |\nabla T \cdot \nabla T|=\frac{1}{V_{T}^{2}},
\end{aligned}
$$

where $t_{P}-T(y)=$ const - equation of the wave front; $t_{P}$ - time of wave propagation; $\left(V_{L} ; V_{T}\right)$ - longitudinal and transversal velocities [2]; $(\lambda ; \mu)$ - Lame's constants.

The NDE of Lame's constants $(\lambda ; \mu)$ is important problem in testing of solid bodies. Interest in practice is the NDE of Lame's constants $(\lambda ; \mu)$, for unilateral access to objects. For NDE of $(\lambda ; \mu)$ by measured $\left(V_{L} ; V_{T}\right)$ the relations $(2)$ are used. In this case a scheme of one-sided access to object is realized [4]. In Fig. 1 the ultrasonic scheme for measuring of ultrasonic velocities is given. In this case the equation (2) reduced to equation (3), which is the Snell's law [3,4].

According to [4], the equation (8) is transform to Snell's law

$$
\frac{V_{T}^{2}}{\sqrt{\left(V_{1}\right)^{2}-V_{T}^{2} \sin ^{2} \vartheta_{1 a}}}=\frac{W}{t_{T} \sin \vartheta_{1 a}},
$$




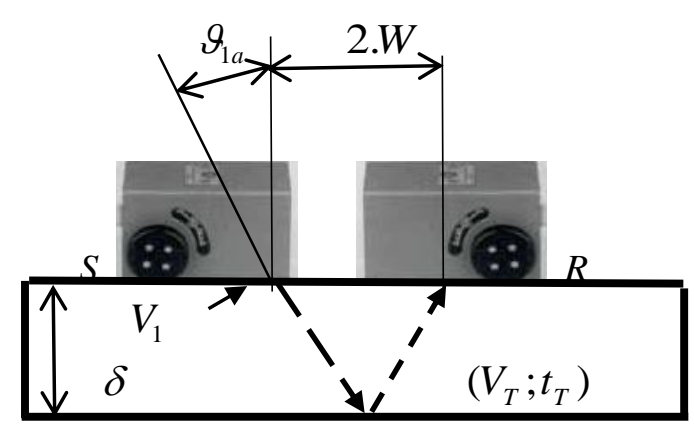

Fig. 1. Pitch and Catch ultrasonic technique.

where $\vartheta_{1 a}$ is the incidence angle, $\vartheta_{1 b} \equiv \vartheta_{1 a}, 2 W$ - the distance between transducers with variable angles (source $-S$; reflector $-R$ ), $V_{1}$ - the ultrasonic velocity in the protector of transducers, $\left(V_{T} ; t_{T}\right)$ is respectively velocity and time of propagation of transversal ultrasonic wave in the sample.

If the incidence angle is $\vartheta_{1 a}=45^{\circ}$, the equation (9) is reduced to

$$
\frac{V_{T}^{2}}{\sqrt{2 V_{1}^{2}-V_{T}^{2}}}-\frac{W}{t_{T}}=0 .
$$

The solution of (10) by the Newton method, the algorithm ZEROIN [2] and the online compiler of $\mathrm{C}^{++}$is solved. Search interval is $\left(V_{T}^{(L)} ; V_{T}^{(R)}\right)(\mathrm{mm} / \mu \mathrm{s})$. The number of iteration $N$ is $N<\log _{2}^{2}[(b-a) / \mathrm{TOL}],(a ; b) \equiv\left(V_{T}^{(L)} ; V_{T}^{(R)}\right)$, TOL $~$ $10^{-6}$ is permissible error. The algorithm ZEROIN is fast approaching and robust.

Equipment for measuring of $\left(V_{T} ; t_{T} ; W\right)$ are two ultrasonic transducers with variable angle (KRAUTKRAMER, Germany), digital ultrasonic flaw detector SITESCAN 150S (SONATEST, England), with measurement accuracy of the time is $0.01 \mu \mathrm{s}$, calibration block (BGN EN ISO 7963:2010), digital caliper (TESA, Austria) with external measurement of the distance $2 W$ and accuracy $0.01 \mathrm{~mm} \mathrm{[2].}$

\section{ApPLiCATIONS OF LAME's CONSTANTS}

\subsection{NDE OF LAME'S CONSTANTS FOR ALUMINUM-SILICON ALLOYS}

The aluminum-silicon alloys, $\mathrm{Al}+3.5 \% \mathrm{Mg}$ alloys, density $\sim 2.7 \mathrm{~g} / \mathrm{cm}^{3}$ is considered.

Measure of velocity of transversal ultrasonic waves, Fig. 1.

The ZEROIN program with data: for organic glass $V_{1}=1.12 \mathrm{~mm} / \mu \mathrm{s}, \delta=$ $30 \mathrm{~mm}, \vartheta_{1 a}=45^{\circ}, 2 W \sim(110 \pm 0.01) \mathrm{mm} ; t_{T} \sim(39 \pm 0.01) \mu$ s is started. The results of ZEROIN program for the roots of (10) in Table 1 are given. 
Table 1.

\begin{tabular}{cc}
\hline \hline $\begin{array}{c}\text { Search intervals set } \\
\left(V_{T}^{(L)} ; V_{T}^{(R)}\right), \quad[\mathrm{mm} / \mu \mathrm{s}]\end{array}$ & $\begin{array}{c}\text { Calculation of roots } V_{T}[\mathrm{~mm} / \mu \mathrm{s}] \text { of }(10) \text { by } \\
\text { ZEROIN algorithm for on-line compiler } \mathrm{C}^{++}\end{array}$ \\
\hline$(0 ; 3)$ & $V_{T}^{(1)} \in C$ \\
$(3 ; 4)$ & $V_{T}^{(2)}=3.249 \pm 0.001 \in R$ \\
$(4 ; 6)$ & $V_{T}^{(3)} \in C ; \quad V_{T}^{(4)} \in C$ \\
\hline \hline
\end{tabular}

The solutions $V_{T}^{(1)}, V_{T}^{(3)}, V_{T}^{(4)}$ are complex roots and dropped out. The value $V_{T}^{(2)}$ is real root and is the solution sought. For comparison, if the reference value is $V_{T}=3.130 \mathrm{~mm} / \mu \mathrm{s}$ [5] and calculated value is $V_{T}^{(2)}=3.249 \pm 0.001 \mathrm{~mm} / \mu \mathrm{s}$. In this case the number of iteration is $\sim 117$. The time of program work is $\sim(5 \div 6) \mathrm{s}$. The error of evaluation of $V_{T}^{(2)}$ is $3.8 \%$. This is a good result for measurement of velocity of transversal ultrasonic wave.

NDE of the constant $\mu$. The velocity $V_{T}^{(2)}=3.249$ is calculated. The NDE of $\mu$ by $\mu=\rho\left(V_{T}^{(2)}\right)^{2}$ is used. The value for shear module $\mu=28.5 \mathrm{GPa}$ is obtain. The reference value (BGN EN 1706) for $\mathrm{Al}+3.5 \% \mathrm{Mg}$ alloys is $\mu \equiv G=26.9 \mathrm{GPa}$. The error of NDE of $\mu$ is $\sim 6 \%$.

NDE of the constant $\lambda$. According to (1) we have $V_{L}^{2}=\lambda+2 \mu$ and, therefore, $\lambda=\rho V_{L}^{2}-2 \mu$, where $\frac{V_{L}^{2}}{V_{T}^{2}}=\frac{2-2 \nu}{1-2 \nu}[2], \nu-$ Poison's ratio. For $\mathrm{Al}+3.5 \% \mathrm{Mg}$ alloys is accepted [6] for middle value of Poison's ratio $\nu \approx 0.32$ (BGN EN 1706). In this case $V_{L} \approx 1.944 V_{T}$. The NDE of $\lambda$ is $\lambda \sim 50.44 \mathrm{GPa}$. Reference value (BGN EN 1706) is $\lambda=48.5 \mathrm{GPa}$. The NDE error of $\lambda$ is $\sim 4.0 \%$.

\subsection{NDE OF HENKY'S CONSTANT FOR ALUMINUM-SILICON ALLOYS}

Theory of small elasticity-plasticity deformations theory is considered. In this case the physical equations (Henky's equations) are [7]

$$
\left(\varepsilon_{i j}-\delta_{i j} \varepsilon_{k k}\right)=\Psi\left(\sigma_{i j}-\delta_{i j} \sigma_{k k}\right), \quad i ; j=1,2,3, \quad \delta_{i j}= \begin{cases}1 & i=j \\ 0 & i \neq j\end{cases}
$$

where $\Psi=\frac{3}{2} \frac{\varepsilon_{i}}{\sigma_{i}}-$ Henky's constant [8], $\left(\varepsilon_{i} ; \sigma_{i}\right)$ are intensities of deformation and of stress. 
For linear zone in "stress-strain diagram". It is know, that [7]:

$$
\Psi=\frac{1}{2 \mu} \text {. }
$$

For plasticity zone in "stress-strain diagram". In this case there are $\varepsilon_{i}=\varepsilon_{x x}-$ $\frac{1}{3 K} \sigma_{x x} ; K=\lambda+\frac{2}{3} \mu ; \sigma_{i}=\sigma_{x x} \equiv \sigma_{Y S}$ [7]. After carrying out the necessary conversion of $\Psi=\frac{3}{2} \frac{\varepsilon_{i}}{\sigma_{i}}$, for Henky's constant it is obtained

$$
\Psi \approx \frac{1}{6 \lambda+4 \mu} .
$$

Example for $\mathrm{Al}+3.5 \% \mathrm{Mg}$ alloys. The velocities $V_{T}=3.249 \pm 0.015 \mathrm{~mm} / \mu \mathrm{s}$ and $V_{L}=6.14 \pm 0.030 \mathrm{~mm} / \mu$ s are calculate. The Lame's constants $\mu=28.5 \mathrm{GPa}$, $\lambda \sim 50.44 \mathrm{GPa}$ are evaluated. The Henky's constants $\Psi=17.5 \mathrm{MPa}$ and $\Psi=$ 2.4 MPa respectively for linear zone and plasticity zone in "stress-strain diagram" are obtained.

\subsection{NDE OF ULTIMATE TENSILE STRESS BY LAME'S CONSTANTS}

For ductile cast iron the relationship between $\sigma_{\mathrm{UTS}}$ and $\left(V_{L} ; V_{T}\right)$ is given in Fig. 2.

For ultrasonic testing of ductile cast iron, the dependencies of type

$$
\sigma_{\text {UTS }} \Leftrightarrow\left(V_{L}\right)
$$

with coefficient of correlation is $\sim 80 \%$ are known [8]. It is good result.

To increase the coefficient of correlation it is necessary to developing a new dependencies of the type $\sigma_{\text {UTS }} \Leftrightarrow\left(V_{L} ; V_{T}\right)$. For the purpose a polynomial regression models from row two with one non-linear predictor as function of $\left(V_{L} ; V_{T}\right)$ is considered. Such dependence is presented in Fig. 2. In this case the regression model, at coefficient of correlation $R \sim 99 \%$, is

$$
\sigma_{\mathrm{UTS}}=\sum_{k=0}^{2} \beta_{2-k}\left[\frac{0.5-\left(V_{T} / V_{L}\right)^{2}}{1-\left(V_{T} / V_{L}\right)^{2}}\right]^{2-k} \mathrm{MPa},
$$

where the velocities $\left(V_{L} ; V_{T}\right) \mathrm{mm} / \mu \mathrm{s}$ according [4] are measured. It is very good result.

In Fig. 2 the tolerance interval $(425 ; 575) \mathrm{MPa}$, for the median value $x=0.25$ at $97.5 \%$ probability is presented.

According to (1) and (2) the model (15) to relationship $\sigma_{\mathrm{UTS}} \Leftrightarrow(\lambda ; \mu)$ is transform, where

$$
\sigma_{U T S}=\sum_{k=0}^{2} \beta_{2-k}\left(\frac{1}{2} \frac{\lambda}{\lambda+\mu}\right)^{2-k} \mathrm{MPa} .
$$




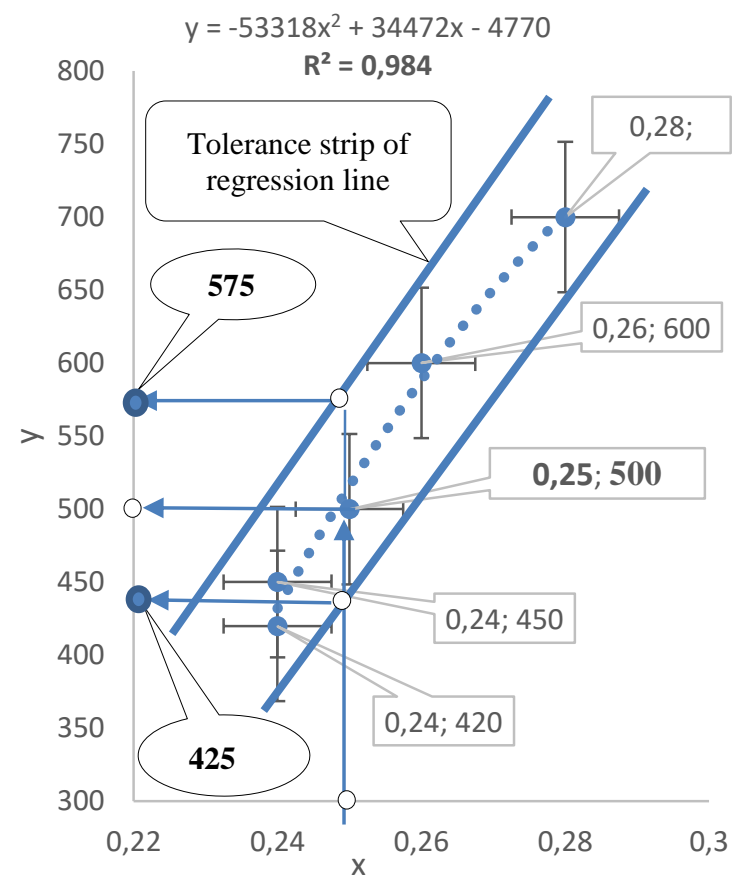

Fig. 2. (Color online) Scatter chart for ductile cast iron, with $95 \%$ confidence intervals for predictor $x$ and the evaluated values $\sigma_{\text {UTS }} \cdot x=\frac{0.5-\left(V_{T} / V_{L}\right)^{2}}{1-\left(V_{T} / V_{L}\right)^{2}} ; y=\sigma_{\text {UTS }}$.

Example for ductile cast iron. The velocities $\left(V_{L} ; V_{T}\right)=(5.85 \pm 0.030 ; 3.38 \pm 0.015)$ are measured. The Lame's constants are $\mu=30.84 \mathrm{GPa} ; \lambda=30.84 \mathrm{MPa}$. Therefore, $x=0.249$. According to (11) $\sigma_{\mathrm{UTS}} \sim 507.76 \mathrm{MPa}$. The NDE errors, relative to the reference value $\sigma_{\mathrm{YS}}=500 \mathrm{MPa}$, is $1.5 \%$.

\subsection{NDE OF THE YIELD STRESS BY LAME'S CONSTANTS}

In theory of elasticity Bussinesq's task is formulate as "To calculate of yield stress

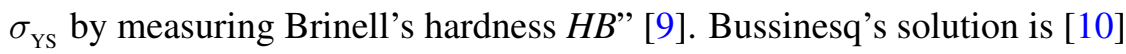

$$
\sigma_{\mathrm{YS}}[\mathrm{MPa}]=k_{\text {Buss }} \varphi(x) H B\left[\mathrm{~kg} / \mathrm{mm}^{2}\right],
$$

where

$$
k_{\text {Buss }} \approx 2.8, \quad \varphi(x)=\left\{\frac{1}{2}(1-2 x)+\frac{2}{9}(1+x)[2(1+x)]^{1 / 2}\right\}, \quad x=\frac{\lambda}{2(\lambda+\mu)} .
$$


Example for $A l+3.5 \% \mathrm{Mg}$ alloys. In this case the velocities are $\left(V_{L} ; V_{T}\right)=$ $(6.36 \pm 0.030 ; 3.15 \pm 0.015) \mathrm{mm} / \mu \mathrm{s}$. The Lame's constants $\mu=28.5 \mathrm{GPa}, \lambda \sim$ $50.44 \mathrm{GPa}$ are evaluated. Then $\sigma_{\mathrm{YS}} \sim 117.04 \mathrm{MPa}$. The NDE errors, relative to the reference value $\sigma_{\mathrm{YS}}=120 \mathrm{MPa}$ (BGN EN 1706), is $2.2 \%$.

\subsection{CRITERIA FOR CLASSIFICATION OF THE TYPE OF FRACTURE FOR SOLIDS}

For this purpose, the concept "size of the plasticity zone at crack tip $r_{P}$ " is considered. In solid mechanics for $r_{P}$ (Irwin's correction), by $(\lambda ; \mu)$, at plain strain, is known [11]

$$
r_{P}(\lambda ; \mu)=\frac{1}{2 \pi}\left(\frac{K_{\mathrm{Ic}}}{\sigma_{\mathrm{YS}}}\right)^{2}\left(\frac{\mu}{\lambda+\mu}\right)^{2}[\mathrm{~mm}],
$$

where $r_{P}(\lambda ; \mu)$ is NDE of $r_{P}$ (also known as Irwin's correction), the values of $\left(K_{\mathrm{Ic}} / \sigma_{\mathrm{YS}}\right)^{2}, \mathrm{~mm}$, for different steel and alloys, in Table 2 and rules of classification of type of fracture in Table 3 are given.

Table 2.

\begin{tabular}{ccc}
\hline \hline \multirow{2}{*}{ Material } & \multicolumn{2}{c}{$\left(K_{I c} / \sigma_{Y S}\right)^{2}, \mathrm{~mm}$} \\
& According to [11] & According to [12] \\
\hline Carbon steel & 43 (middle carbon steel) & 7.2 (low carbon steel) \\
Chrome steel & 0.9 & 0.4 \\
Aluminum alloy & 3.1 & 7.4 \\
Titanium alloy & 4.8 & 4.6 \\
\hline \hline
\end{tabular}

Table 3.

\begin{tabular}{ccc}
\hline \hline Type of condition & Type of fracture & Fracture mechanics \\
\hline$r_{P}(\lambda ; \mu) \rightarrow 0$ & Crispy & Linear \\
$r_{P}(\lambda ; \mu) \leq\left(h_{U T} ; L\right)$ & Quasi-crispy & Linear \\
$r_{P}(\lambda ; \mu) \sim\left(h_{U T} ; L\right)$ & Quasi-viscous & Non-linear \\
$r_{P}(\lambda ; \mu)>>\left(h_{U T} ; L\right)$ & Viscous & Non-linear \\
\hline \hline
\end{tabular}

$r_{P}(\lambda ; \mu)$ is NDE of size of the plasticity zone at crack tip, $\left(L ; h_{\mathrm{UT}}\right)$ are respectively sizes of the depth of crack (measured by digital ultrasonic flaw detector, according ASTM E 2373:2014) and the thickness of testing object (measure by means digital caliper). 
Example for $\mathrm{Al}+3.5 \% \mathrm{Mg}$ alloys. The velocity $\left(V_{L} ; V_{T}\right)=(6.36 \pm 0.030 ; 3.15 \pm 0.015)$ are measured and $\mu=28.5 \mathrm{GPa}, \lambda \sim 50.44 \mathrm{GPa}$ are evaluated. According to (18) and Table $2, r_{P}=(0.226 ; 0.199)<0.25$ respectively according $[11,12]$ are calculated. If condition is $0.25 \leq\left(h_{\mathrm{UT}} ; L\right)$, then the type of fracture, is quasi-crispy. Therefore, Table 3 , the condition for linear fracture mechanics is fulfilled.

\section{CONCLUSiON}

In this article the following innovative results are obtaines:

a) The methodology for evaluation of velocities $\left(V_{L} ; V_{T}\right)$ at unilateral access to tested object, is given. It is very important task in the theory of the ultrasonic testing.

b) A new relationships for NDE, at unilateral access to tested object, of: Lame's constants $(\lambda ; \mu)$ in theory of elasticity, Henky's constant $\Psi$ in theory of small elasticity-plasticity deformation (for elasticity and plasticity zones in "stressstrain diagram".), ultimate tensile stress $\sigma_{\mathrm{UTS}}$, yield stress $\sigma_{\mathrm{YS}}$, the rules of decision for classification of type of fracture by the size of the plasticity zone at crack tip, in plain strain $r_{P}$ are obtain. This rules by $(\lambda ; \mu)$ and $\left(h_{\mathrm{UT}} ; L\right)$ are described. These are important tasks in the mechanics of materials and fracture mechanics. For aluminum alloy and ductile cast iron examples are given.

The methods, considered in this article, for NDE of elasticity modulus and mechanical properties, allow evaluating directly on the tested detail. It is a typical NDE task.

\section{REFERENCES}

[1] I.V. SoKolNikov (1972) "Mathematical Theory of Elasticity". Nauka i Izkustvo, Sofia (in Bulgarian).

[2] G.E. Forsythe, M. Malcolm, C. Moler (1977) "Computer Methods for Mathematical Computations". Prentice-Hall Inc., New York.

[3] G.B. Whitham (1974) "Linear and Nonlinear Waves". John Wiley \& Sons, New York (in Russian).

[4] ASTM E494-15 (2015) Standard Practice for Measuring Ultrasonic Velocity in Materials. USA; https://www.astm.org/Standards/E494.htm.

[5] I.N. ERmolov, A.H. Vopilkin, V.G. Badalian (2000) "Ultrasonic Calculations". NPC "Eho+", Moscow (in Russian).

[6] D.I. Dimov (1972) "Tables and Formulas in Mechanics of Materials". Tehnika, Sofia (in Bulgarian)

[7] G.S. Pisarenko, N.S. MojarovskiI (1981) "Equations and boundary tasks in plasticity ad creep theory". Naukova dumka, Kiev (in Russian). 
[8] E.S. Ivanushinin, G.S. Belay (1984) "Ultrasonic Testing of Castings". Technika, Kiev (in Russian).

[9] S.P. Timoshenko, J. Gudier (1979) “Theory of Elasticity”. Nauka, Moscow (in Rusian).

[10] M.P. Markovitz (1983) "Not-Samples Methods for Evaluation of Mechanical Properties of Metals". MEI, Moscow (in Russian).

[11] I.M. Kernshtein ET AL. (1989) "Fundamentals of Fracture Mechanics". Moscow State University (in Russian).

[12] A.E. Andreykiv (1982) "Spatial Tasks in the Theory of Cracks". Naukova dumka, Kiev (in Russian). 